\title{
"Vamos tirar a educação do vermelho": o Escola Sem Partido nas redes digitais
}

\author{
Richard Romancini
}

\section{Resumo}

0 artigo apresenta um estudo de caso do movimento

Escola Sem Partido (ESP), que combina análises

da cobertura noticiosa e da atuação de indivíduos

e instituições que utilizam a rede social Twitter (a partir da hashtag \# escolasempartido). 0 pano de fundo teórico envolve a questão da midiatização da política e 0 ativismo digital contemporâneo. Em termos de resultados, é possível destacar: a cobertura dos meios informativos é geralmente neutra ou desfavorável ao ESP; a discussão no Twitter é realizada majoritariamente pelos apoiadores da causa, com uso significativo de meios de comunicação de baixa qualidade; muitos tweets utilizam técnicas da mídia participativa.

\section{Palavras-Chave}

Escola Sem Partido. Ativismo digital. Midiatização.
Richard Romancini | richardromancini@usp.br Doutor em Ciências da Comunicação pela Universidade de São Paulo USP, Brasil. Professor adjunto da USP.

\section{Introdução}

Surgido em 2004, o chamado movimento Escola Sem Partido (ESP) ganhou impulso no Brasil dez anos depois, quando projetos inspirados por ele passaram a ser apresentados em diferentes órgãos legislativos. Criticado por pesquisadores e profissionais, o ESP tem recebido a atenção de estudos, principalmente na área da educação (e.g., AÇÃO EDUCATIVA, 2016; FRIGOTTO, 2017). Há consenso nessa literatura a respeito de 0 ESP representar uma face da ascensão ou reação conservadora no país.

0 ESP teve, desde o seu início, uma relação com o ambiente digital, pois surgiu a partir de um site, ainda hoje existente, que divulga as suas propostas $^{1}$ e recebe denúncias de "doutrinação ideológica" em escolas, além de possuir perfis próprios nas redes sociais Facebook (com quase 160 mil seguidores) e Twitter (cerca de 11 mil seguidores) $)^{2}$. 0 movimento parece ter compreendido, como outros atores políticos de direita, que suas causas podem ser, hoje, 
articuladas e disseminadas pela internet

(ENGESSER et al., 2017).

A adoção das novas tecnologias pelos movimentos conservadores pode parecer contraditória, em razão do antimodernismo que os caracteriza ${ }^{3}$. Porém, a literatura mostra como esses movimentos também procuram tirar vantagem da capacidade de aliciamento da internet, com a ação de pessoas comuns (e.g., ATTON, 2006; EKMAN, 2014), que faz, inclusive, com que elas se sintam mais incluídas na causa (SIMPSON; DRUXES, 2015, p. 7).

Além de mostrar a especificidade do uso da tecnologia digital por ativistas conservadores, temos, neste trabalho, a oportunidade de discutir como teorias sobre os movimentos sociais e suas práticas comunicativas na internet colaboram na compreensão dessa causa. Desse modo, 0 artigo tem como objetivos principais: 1) analisar como os órgãos noticiosos têm feito a cobertura do ESP; 2) perceber quais são os indivíduos e instituições que participam da conversação sobre o movimento no Twitter; 3) verificar características dos conteúdos do Twitter quanto ao uso de mídia, de modo a analisar a relação dos tweets com a cobertura midiática do movimento e a produção de conteúdos pelos usuários.

\section{Procedimentos metodológicos e questões de pesquisa}

0 estudo do caso foi realizado a partir de informações bibliográficas sobre 0 Escola Sem Partido, por meio da coleta de conteúdos jornalísticos ${ }^{4}$ e de tweets $^{5}$ sobre 0 movimento. Há limitações nas duas amostras: assim, a coleta de matérias jornalísticas via buscador de internet, está sujeita aos critérios de "relevância" da ferramenta, bem como ignora os conteúdos protegidos ou fora da internet. A despeito disso, o corpus elaborado, ainda que não estritamente representativo do universo (cobertura do ESP pela imprensa), oferece pistas sobre o que as pessoas

Disponível em: <http://www.escolasempartido.org/>. Acesso em 20 nov. 2017.

Disponíveis, respectivamente, em <https://pt-br.facebook.com/pg/escolasempartidooficial> e <https://twitter.com/ escolasempartid >. Acesso em 20 dez. 2017. Além disso, a internet é utilizada para motivos mais prosaicos, como a venda de camisetas, ver: <https://goo.gl/y8KsgH>. Acesso em 20 dez. 2017.

Para Rucht (2004), os movimentos "progressistas" tendem a trabalhar mais questões que envolvem a mídia do que os conservadores. Entretanto, Cammaerts (2009) observa que 0 uso da mídia pelos diferentes movimentos reacionários talvez seja sub-estudado.

A estratégia envolveu a pesquisa, no buscador Google, no dia 28 de dezembro de 2017, com o termo "escola sem partido", no modo de "navegação anônima" (para impedir a influência de buscas anteriores), e posterior coleta das cem primeiras matérias sobre 0 ESP. Só foram coletados conteúdos de fontes dedicadas primordialmente à produção jornalística. Essa opção justificase pela tentativa de perceber como veículos mais propensos a serem lidos pelas pessoas comuns abordam a causa, podendo influenciar esses indivíduos.

Foram coletados todos os que possuíam a hashtag \#escolasempartido, num período de sete meses (de 28 de maio a 28 de dezembro de 2017). A provável existência do ativismo de pessoas comuns justificou essa escolha. 
que buscam informação sobre o movimento encontram na rede e, no agregado, compõe uma amostra de conveniência do que a mídia na web publica sobre $0 \mathrm{ESP}^{6}$.

0s tweets (8.365 no total) ${ }^{7}$ foram coletados com o uso da ferramenta digital TAGS, e depois transferidos para outro programa (Tableau) por meio do qual foram extraídos dados para a análise. Em relação às limitações dessa amostra, nota-se que, embora as hashtags tenham a vantagem de estruturar as discussões no Twitter, nem todas as mensagens sobre 0 assunto são captadas. Porém, o uso de hashtag indica certo compromisso em participar de discussão mais geral (BRUNS; BURGESS, 2015). E, de modo a favorecer a representatividade da amostra, foram feitos testes com outras hashtags, sendo a mais promissora escolhida.

Os materiais de imprensa foram submetidos a uma análise de conteúdo (BAUER, 2002) a partir de variáveis predefinidas. 0 mesmo ocorre com os tweets, classificados em categorias temáticas relacionadas às questões da investigação. Em consonância com a discussão teórica apresentada na sequência e com os objetivos do estudo, as seguintes questões de pesquisa norteiam as análises do trabalho:
- quais relações podem ser estabelecidas entre a cobertura noticiosa voltada ao Escola Sem Partido e a circulação de conteúdos sobre esse movimento no Twitter, e como isso se reflete nas estratégias de comunicação do movimento?

- quais são os tipos de conteúdos midiáticos que se associam aos tweets produzidos pelos usuários participantes da discussão, e como essa característica pode ser explicada?

- é possível entender a discussão como uma instância da chamada "nova direita" brasileira, que tem encontrado espaço nas redes sociais?

\section{Dimensões teóricas}

\section{A midiatização da política e os movimentos sociais}

Como parte da ampla dinâmica de midiatização da sociedade, ocorre também a midiatização da política, que pode ser definida, de maneira sintética, como um processo pelo qual as instituições e os atores desta esfera passam a ser cada vez mais influenciados pela mídia (STRÖMBÄCK; ESSER, 2014, p. 4; FIGUEIRAS,

Os dados dessas matérias foram organizados numa planilha e, para dar mais transparência à pesquisa, este arquivo foi colocado on-line: <https://goo.gl/RFZX9L>. Acesso em 10 jan. 2018.

Também inseridos numa planilha digital, pela mesma razão da amostra anterior, no seguinte endereço: <https://goo.gl/ mAe7JU>. Acesso em 10 jan. 2018. 
2017, p. 37). Afirma-se que a midiatização da política, ao aproximar a figura do eleitor e a do consumidor (principalmente no âmbito eleitoral), tornando os candidatos cada vez mais indiferenciados, tem estimulado os movimentos sociais, de modo paradoxal. Isso ocorre, pois 0 desencanto sentido por muitos indivíduos com a política tradicional faz com que parte deles procure outras formas de engajamento social, entre elas a política de protesto (CABLE, 2017, p. 186).

Outro ponto que reforça os processos de midiatização social e de mobilização política é a ampla adoção das novas mídias e dispositivos comunicacionais, o que permite que as pessoas se comuniquem, produzam e propagem conteúdos com facilidade (MAZZOLENI, 2014). Em certa medida, as práticas de ativismo digital - ou seja, as ações políticas dos cidadãos apoiadas por tecnologias e plataformas digitais - ganharam impulso por essa dinâmica.

A midiatização da política envolve aspectos que afetam as instituições e práticas nesse domínio, com reflexos no ativismo, tendo em vista que a mídia é uma fonte de informação e irradiação de mensagens central para os movimentos sociais, afetando o modo como eles atuam. É claro, como discute Rucht (2004), que nem todo movimento social procura atingir uma ampla audiência; alguns preferem mobilizações qualitativas8. Porém, há movimentos que almejam influir em decisões políticas, caso do ESP $^{9}$, o que torna as mobilizações quantitativas fundamentais. Assim, devido ao alcance atual da mídia e à dependência que os detentores do poder têm da opinião pública, Rucht formula a "hipótese de que as reações dos meios de comunicação de massa são uma condição prévia para o sucesso ou o fracasso final desses movimentos"10 (2004, p. 27; tradução nossa).

Para conseguir a cobertura dos meios de comunicação, os movimentos sociais buscam, muitas vezes, formas de se anteciparem ou se adaptarem ao comportamento da mídia. Nem sempre, porém, isso garante a atenção ou uma cobertura favorável e, por isso, os ativistas desenvolvem estratégias para reagir ou contornar esse problema. Rucht (2004) identifica quatro principais formas de reação: abstenção, ataque, adaptação e alternativas.

Na abstenção, a ausência de ressonância na mídia ou as experiências negativas nessa esfera

Nesse caso, baseadas na presencialidade, como nos movimentos feministas nas décadas de 1970 e 1980 .

Podemos entender o ESP como um movimento social, pois ele apresenta aspectos que a literatura indica como característicos desse tipo empírico, ou seja, é uma rede de indivíduos, que se aglutina a partir de um propósito específico, compartilhando uma identidade entre os participantes, e que busca alcançar seus objetivos, confrontando-se e interagindo com determinadas pessoas (CABLE, 2017, p. 186).

10 No original: "[We can] hypothesize that reactions of the mass media are a precondition for the ultimate success or failure of these movements". 
levam o movimento social a desistir de ter influência nos meios. Na modalidade de ataque, os ativistas que se sentem mal representados ou negligenciados pela mídia realizam ações de crítica e protesto (cartas, abaixo-assinados etc.). A adaptação envolve a tentativa de influenciar os meios de comunicação, a partir da aceitação das regras e normas da mídia, o que pode levar à contratação de jornalistas ou relações-públicas. Por fim, a busca de alternativas, favorecida atualmente pelas tecnologias digitais (RUCHT, 2013), relaciona-se com a criação de veículos ou fóruns públicos de discussões próprios. A disseminação da internet possibilita formas de reação à falta de atenção da mídia tradicional, pela produção midiática num modelo de "autocomunicação massiva" (CASTELLS, 2009).

\section{Debate público na internet e comunicação de grupos extremistas}

As formas como um movimento social procura produzir comunicação não são mutuamente excludentes ou estáticas. Ao longo do tempo, as situações podem mudar, implicando adaptações. Porém, seja qual for o método (ou métodos) que se utilize(m), é certo que a produção discursiva dos movimentos sociais (e daqueles que se opõem a eles) ocupa algum lugar nas esferas de debate da sociedade, representando, ao mesmo tempo, um elemento central no processo de constituição do próprio movimento.

As análises pioneiras de espaços digitais de ultradireita, como a de Atton (2006), destacaram 0 teor verticalizado e 0 "fechamento" da comunicação efetuada. No entanto, em função das rápidas mudanças no panorama midiático, é válido indagar "em que medida nosso entendimento sobre as operações da ultradireita ainda é aplicável no tempo das plataformas interativas online e da mídia social"11 (PADOVANI, 2016, p. 403, tradução nossa).

Além disso, é necessário pensar nas características intrínsecas da mídia adotada por certo grupo. Nota-se, nessa perspectiva, que 0 formato de comunicação do Twitter - limitado a 280 caracteres (antes do final de 2017, eram 140) - parece oferecer mais oportunidades para os participantes de movimentos políticos extremistas, já que podem prescindir de elevado desenvolvimento argumentativo (VAN KESSEL; CASTELEIN, 2016).

\section{A "nova" direita no Brasil}

Pierucci notara que, no Brasil, "os homens de direita que se declaram de direita, que 'se assumem', são bem raros" (1987, p. 19). Essa realidade, explicada entre outros aspectos pela 
associação entre 0 ideário conservador e 0 regime militar, entretanto, mudou nos últimos anos. Daí, o crescente uso da metáfora de "sair do armário", para referir-se ao processo de maior visibilidade e autoidentificação de indivíduos e grupos como "de direita", em textos jornalísticos e acadêmicos (e.g., SOLNIK, 2012; MESSENBERG, 2017).

Essa mudança é analisada por acadêmicos (e.g., VELASCO E CRUZ; KAYSEL; CODAS, 2015) que tendem a justificá-la por razões como a "estafa do lulismo" (DELCOURT, 2016, p. 136), combinada à perda de confiança no governo e nas elites políticas, devido aos casos de corrupção, à crise econômica dos últimos anos e a a aproveitamento oportunista por parte dos neoconservadores dos protestos de 2013. Alguns dos estudos também destacam o papel das redes sociais na mobilização conservadora (SILVEIRA, 2015; SILVA JUNIOR, 2016;

TELLES, 2016). Assim, esses trabalhos indicam características desse agrupamento (como 0 caráter frouxamente institucional e 0 tipo de agenda) que serão úteis para avaliar, a partir das análises, se o ESP pode ser visto como uma das "ondas" da "maré" da nova direita"12.

\section{Estudo de caso: 0 ativismo conservador do Escola Sem Partido}

\section{Breve contextualização do movimento}

Conforme as palavras do advogado e procurador Miguel Nagib, idealizador do ESP, o movimento foi "inspirado em alguns sites americanos ${ }^{13},[\ldots]$ para que as vítimas da doutrinação em sala de aula pudessem relatar suas experiências, de modo que com 0 tempo nós tivéssemos um bom acervo de provas da existência do fenômeno" (apud DIP, 2016). Dez anos depois de sua criação, o ESP passou a ganhar força, durante as manifestações contra a presidente Dilma Rousseff, em 2014. Nesse contexto, ele conquistou 0 apoio de várias personalidades, grupos (como o Movimento Brasil Livre - MBL) e políticos conservadores.

0 "acervo de provas" da doutrinação passou a ser utilizado com mais frequência em denúncias a professores ${ }^{14}$. Projetos de lei (PL) inspirados e apoiados pelo movimento passaram a ser apresentados em legislativos do país por políticos de direita. A respeito do suporte legal dado pelo ESP, hoje, quem entra no site da causa logo recebe a indicação de outro endereço eletrônico ${ }^{15}$, com a

12 A metáfora é de Ronaldo Almeida, citado em Faganello (2015).

13 Fontes de influência estrangeira para o ESP, como a iniciativa No Indoctrination, dos Estados Unidos, são apontadas no trabalho de Espinosa e Queiroz (2017). Estes autores também notam, analisando a rede de atores do ESP, a ampla atuação de pessoas envolvidas em causas e instituições conservadoras, o que contradiz o caráter "apartidário" com que o movimento tenta se apresentar.

14 Alguns exemplos são mostrados na reportagem de Dip (2016).

15 Disponível em: <https://www.programaescolasempartido.org/>. Acesso em 20 nov. 2017. 
sugestão de textos legislativos relacionados ao programa.

As propostas de PL utilizam uma linguagem na qual os estudantes são uma "audiência cativa" que não deve ser submetida à "manipulação psicológica". Contra os "professores doutrinadores", é apresentado o instrumento da denúncia anônima. A ideia tem culminância prática na proposta de que as salas de aula de educação básica tenham um cartaz com os "Deveres do Professor" ${ }^{\prime \prime}$. Entre estes, o de não promover os seus "próprios interesses, opiniões, concepções ou preferências ideológicas" e apresentar "aos alunos, de forma justa [...] as principais versões, teorias, opiniões e perspectivas concorrentes a respeito da matéria".

0s pesquisadores da educação notam que esses projetos de lei representam um cerceamento à liberdade e à autonomia do ensino, impondo dispositivos de controle externos às escolas (ALMEIDA NETO; SILVA, 2017). A suposta preocupação "pluralista" do ESP é associada, de maneira contraditória, com a proposta de apresentação "neutra" de conteúdos e perspectivas. Isso pode representar contrassensos, como exposições "neutras" do ponto de vista negacionista sobre o Holocausto ou os professores serem impedidos de explicar a razão de uma greve (pois iriam "promover seus interesses").
Miguel (2016) nota que o crescimento do ESP deu-se a partir da confluência do movimento antes focado na "doutrinação ideológica" - com o combate à chamada "ideologia de gênero". Há, nessa associação entre moral e política, a defesa da prevalência dos valores "familiares" sobre os ensinados nas escolas. 0 ESP defende, desse modo, a distinção entre a instrução, que deveria ser "neutra", "não ideológica", a cargo da escola, e a educação, imbuída de valores, porém, realizada no âmbito da família e de acordo com as suas crenças. Para analistas, tal concepção é uma forma de defesa de interesses da classe dominante (RAMOS, 2017), em prol de uma educação tecnicista e conservadora (PENNA, 2017).

\section{A cobertura da imprensa}

As 100 matérias de imprensa sobre o ESP analisadas compreendem o período de 30 de junho de 2016 a 19 de dezembro de 2017, sendo a maioria (83) do ano de 2017. Embora a amostra não seja estatística, o número e 0 alcance do tema não parecem irrelevantes em veículos de diferente porte. Desse modo, quanto ao tipo de veículo que as publicaram, observa-se que a categoria mais comum foi a grande mídia, isto é, os veículos de maior apelo nacional (jornais como a Folha de S. Paulo, ou portais como o G1), com 33 matérias, sendo seguida pelas publicações em veículos alternativos de alcance variado (por exemplo, Carta Maior), com 29 publicações; 
as matérias em veículos regionais (Diário do Grande ABC, Portal Paraná, etc.) somam 23 e, por fim, os conteúdos em mídias especializadas (principalmente em educação) foram 15.

A categorização sobre a natureza dos conteúdos (o que é abordado com mais ênfase) conclui que, em primeiro lugar, estão os projetos legislativos, com 38 matérias, relatando 0 andamento de propostas pelo país. Em seguida, estão descrições e análises críticas sobre o ESP, com 33 matérias, sendo que 0 adjetivo "críticas" remete ao maior destaque aos aspectos problemáticos do tema (a partir das fontes ou da análise dos autores); a cobertura de protestos e mobilizações teve 11 matérias; os posicionamentos do judiciário e da $O N U$ sobre ele somam dez conteúdos; sete reportagens abrangem outros temas e, por fim, há somente três matérias com defesa das posições do movimento. Nesse caso, elas foram publicadas em veículos de menor expressão: um portal jurídico, um site econômico e outro religioso. Esse dado está relacionado à descrição da última categorização relevante. Ao classificar o "viés" das matérias sobre o ESP, nota-se que a maioria adota uma abordagem neutra (55), equilibrando prós e contras da proposta, ou opta pela forma descritiva, mas as matérias nas quais o teor geral é negativo são 42 e, como notado, apenas três defendem 0 ESP.
As abordagens críticas não estão somente em matérias opinativas, na verdade, a maior parte dos conteúdos da categoria descrições e análises críticas sobre o ESP é de reportagens que oferecem informações sobre o movimento. A cobertura midiática neutra ou negativa ao ESP não se deve ao eventual "esquerdismo" dos veículos jornalísticos ${ }^{17}$. Na verdade, até um colunista conservador como Reinaldo Azevedo (2017) o critica. A Folha de S.Paulo (2016), jornal de referência no qual Azevedo atua, publicou editorial que deplora as iniciativas legislativas inspiradas pelo ESP.

A cobertura é desejada pelo ESP, inclusive pelos políticos que 0 apoiam, como forma de adquirir projeção. Por isso, o movimento não adota estratégias sistemáticas de abstenção. Busca-se exposição, mas, até agora, sem sucesso qualitativo: não atrai o apoio de jornalistas ou órgãos informativos expressivos, mas sim do "baixo clero" intelectual e político. Isso reforça a importância da criação de canais de mídia pelo próprio movimento. A estratégia de desenvolvimento de mídia alternativa é clara, pelos próprios sites do movimento já citados. A análise dos tweets sobre o ESP oferece, porém, elementos para compreender essa outra forma de mídia alternativa, na qual também poderemos ver se ocorrem ataques à mídia. Compreender 0 grau 
de adaptação exigiria estratégias de pesquisa não realizadas.

\section{A hashtag \# escolasempartido no Twitter}

Do total de 8.365 mensagens do corpus, notase que 5.662 foram retweets, 1.692 tweets originaise1.011@mentions (tweets com menções a outros usuários). Há 4.574

perfis que participaram ativamente dessa espécie de conversão mediada pela hashtag, produzindo algum conteúdo. As Tabelas 1 e 2 mostram, respectivamente, características dos usuários mais ativos (número de tweets) e com maior visibilidade (retweets e menções recebidas).

Tabela 1: Usuários com maior atividade na discussão ao redor da hashtag \#escolasempartido

\begin{tabular}{|c|c|c|c|c|}
\hline Usuário & Tipo de perfil & Tweets* & Seguidores & Caracterização do perfil \\
\hline @usuario1 & Pessoal & $180(129)$ & 4.274 & Nacionalista \\
\hline @usuario2 & Pessoal & $46(17)$ & 5.157 & Bolsonarista \\
\hline @usuario3 & Pessoal & $44(16)$ & 3.413 & Antilulista \\
\hline @usuario4 & Pessoal & $37(36)$ & 841 & Apoiador da operação Lava Jato \\
\hline @usuario5 & Pessoal & $33(6)$ & 752 & Nacionalista \\
\hline @usuario6 & Pessoal & $31(18)$ & 2.465 & Apoiadora da operação Lava Jato \\
\hline @usuario7 & Pessoal & $31(8)$ & 657 & Professor antiTemer \\
\hline @usuario8 & Pessoal & $31(14)$ & 17.200 & Apoiadora da operação Lava Jato \\
\hline @usuario9 & Pessoal & $30(13)$ & 896 & Bolsonarista \\
\hline @usuario10 & Pessoal & $29(9)$ & 10.500 & Anticomunista \\
\hline @CristPolit & Institucional & $28(1)$ & 32.000 & Portal noticioso cristão, "democrata" \\
\hline @usuario11 & Pessoal & $27(26)$ & 195 & Bolsonarista \\
\hline @usuario12 & Pessoal & $26(1)$ & 1.578 & Antilulista, apoiadora da Lava Jato \\
\hline @DepSostenes & Pessoal & $25(10)$ & 39.500 & Deputado federal. "Defensor da vida e da família!" \\
\hline @usuario13 & Pessoal & $24(7)$ & 5.738 & Conservadora \\
\hline @usuario14 & Pessoal & $24(1)$ & 1.230 & Separatista sulista \\
\hline @usuario15 & Pessoal & $23(1)$ & 195 & Nacionalista \\
\hline @usuario16 & Pessoal & $22(6)$ & 1.164 & Evangélico, contra intolerância religiosa \\
\hline @MBLivreBH & Institucional & $21(16)$ & 312 & Perfil oficial do Movimento Brasil Livre de Belo Horizonte \\
\hline @usuario17 & Pessoal & $21(6)$ & 548 & Antilulista, antipetista \\
\hline
\end{tabular}


Tabela 2: Usuários com maior visibilidade na discussão ao redor da hashtag \#escolasempartido

\begin{tabular}{|c|c|c|c|c|}
\hline Usuário & Tipo de perfil & Retweets e menções* & Seguidores & Caracterização do perfil \\
\hline @usuario8 & Pessoal & $996(988)$ & 17.200 & Apoiadora da operação Lava Jato \\
\hline @usuario1 & Pessoal & $752(736)$ & 4.274 & Nacionalista \\
\hline @usuario18 & Pessoal & $503(501)$ & 18.000 & Bolsonarista \\
\hline @bolsonarosp & Pessoal & $469(416)$ & 274.000 & Bolsonarista \\
\hline @usuario19 & Pessoal & $455(451)$ & 45.500 & Conservador, "Contra Politicamente Correto" \\
\hline @usuario20 & Pessoal & $252(252)$ & 7.771 & Antipetista, anticutista \\
\hline @usuario6 & Pessoal & $149(147)$ & 2.465 & Apoiadora da operação Lava Jato \\
\hline @usuario21 & Pessoal & $145(142)$ & 5.275 & Procurador da República, cristão \\
\hline @usuario22 & Pessoal & 140(139) & 17 & Bolsonarista \\
\hline @usuario3 & Pessoal & $131(127)$ & 3.413 & Antilulista \\
\hline @alemd4ssombras & Institucional & $85(83)$ & 4.180 & Notícias para esclarecer as pessoas \\
\hline @usuario23 & Pessoal & $80(77)$ & 8.003 & Antipetista \\
\hline @conexaopolitica & Institucional & $69(65)$ & 38.600 & Notícias "com viés cristão, conservador, de direita" \\
\hline @usuario24 & Pessoal & $66(66)$ & 2.518 & Cartunista (crítico ao ESP) \\
\hline @antesdepoisfede & Institucional & $62(62)$ & 35.500 & Humor (direita alternativa) \\
\hline @usuario25 & Pessoal & $48(40)$ & 17.600 & Antilulista \\
\hline @usuario26 & Pessoal & $45(31)$ & 15.700 & Antilulista, anticomunista e anticorrupção \\
\hline @DepSostenes & Pessoal & $45(43)$ & 39.500 & Deputado federal. "Defensor da vida e da família!" \\
\hline @0deCarvalho & Pessoal & $44(41)$ & 218.000 & "Filósofo" e jornalista \\
\hline @usuario2 & Pessoal & $34(32)$ & 5.157 & Bolsonarista \\
\hline @usuario27 & Pessoal & $33(33)$ & 3.516 & Antissocialista \\
\hline \multicolumn{5}{|c|}{$\begin{array}{c}\text { * Entre parênteses o número de retweets } \\
\text { Fonte: Elaboração do autor }\end{array}$} \\
\hline
\end{tabular}

Essa discussão desenvolve-se, majoritariamente

- como se poderia esperar -, pelos apoiadores do movimento. Desse modo, ao somarmos os 20 perfis de usuários com maior produção de conteúdos aos 20 com maior visibilidade (os que produziram conteúdos mais retweetados e com mais menções), chegamos a um número de 35 perfis (pois se excluem os que se sobrepõem nos dois grupos, em itálico na Tabela 2). E, desse total, apenas quatro perfis (em negrito, nas duas tabelas) não podem ser considerados apoiadores do ESP, os outros 310 são.
A análise dos tweets também fortalece esse juízo: do total de 8.365 tweets, 7.615 (91\%) foram favoráveis ao ESP, contra 750 (9\%) contrários (maioria nesse subgrupo) ou neutros.

Preferiu-se deixar anônimos os usuários comuns, destacando apenas os indivíduos e perfis (institucionais) com funções ou atividades públicas. Nesse caso, temos os deputados federais Sóstenes Cavalcante (DEM-RJ), membro da bancada evangélica, e Eduardo Bolsonaro (PSC-SP) - que 
possui o perfil com maior alcance no grupo, com 274 mil seguidores -, ambos defensores do ESP, e do guru da direita brasileira Olavo de Carvalho (também bastante seguido: 218 mil usuários). Observa-se, assim, uma participação minoritária de perfis institucionais na discussão ao redor da hashtag.

Os indivíduos apoiadores do ESP podem ser classificados como conservadores. A categorização do perfil político deu-se pelas imagens e textos das contas dos usuários. Foi significativo, aliás, perceber a relevância de autodeclarações políticas nesse espaço. 0 Twitter parece ser utilizado, em grande medida, como forma de participação política por essas pessoas. Os adjetivos com que se autodescrevem, ou que se pode inferir do que dizem ou mostram, indicam sobreposições, tanto em termos de demarcadores positivos nacionalismo, bolsonarismo, religiosidade -, quanto negativos - antiesquerdismo e anticorrupção (daí, as demonstrações de apoio à operação Lava Jato) ${ }^{18}$ -, que se cruzam na identificação do Partido dos Trabalhadores (PT) como inimigo comum.

Esse aspecto é importante para caracterizar 0 ESP, pois, como nota Delcourt, o "antipetismo constitui o principal cimento" (2016, p. 129) ${ }^{19}$ da nova direita brasileira. Messenberg (2017) observa que o "antipetismo" é o maior campo semântico nas emissões discursivas, on-line ou não, dos formadores de opinião dessa direita. De fato, os grupos conservadores usam bastante as redes sociais. De acordo com Silveira, em 2015, "as principais lideranças da direita nas redes conseguiam levar suas mensagens nas redes sociais para uma audiência diária em torno de 40 milhões de pessoas" (2015, p. 228).

Voltando ao grupo de usuários em análise, há a rejeição ao "petismo", mas nenhum partido empolga essas pessoas. De maneira significativa, os dois perfis de deputados mencionados não informam o partido ao qual eles pertencem. São "indignados", como alguns se autodescrevem, que tendem a apoiar pessoas (por isso o apelo de Jair Bolsonaro e, em menor grau, do juiz Sergio Moro) ou causas (como o ESP) e não partidos. Essa observação é convergente com 0 antipartidarismo que caracteriza a rede de canais antipetistas do Facebook, estudada por Santos Junior (2016), como dimensão significativa da nova direita no contexto on-line.

18 São indicadores de características como as mencionadas, as imagens escolhidas pelos usuários para inserção no topo de suas páginas iniciais na plataforma, as próprias fotos (ou imagens, eventualmente com mensagens textuais) dos perfis e as autodescrições de apresentação do usuário. Assim, o "nacionalismo" é perceptível pelo uso de símbolos patrióticos (bandeira, mapa, cores do Brasil, etc.) ou o "antipetismo" por declarações (na descrição do perfil) como essa: "As pessoas boas devem amar seus inimigos. Exceto petistas".

19 Outros trabalhos, como os de Saad-Filho e Boito (2015), Santos Junior (2016) e Telles (2016), discutem a associação entre a nova direita e 0 antipetismo. Ao caracterizar os participantes de protestos de direita brasileiros, Tatagiba, Trindade e Teixeira notam que o "que os une, desde 2007, é a luta contra o PT e contra a corrupção, a partir de um discurso que associa os governos petistas ao mau uso da máquina pública” (2015, p. 198). 
Quanto às variáveis de gênero e idade dos

principais participantes da conversação,

temos 20 homens, dez mulheres (e cinco perfis

institucionais) e, pela observação das imagens dos

perfis, é possível inferir que a grande maioria dos

participantes é de indivíduos de meia-idade. Feita

essa descrição dos usuários mais ativos e com

mais visibilidade, podemos avançar na análise dos

conteúdos dos tweets.

Em consonância com as preocupações da pesquisa, classificamos os tweets (contrários/ neutros e favoráveis ao ESP) em termos de eles possuírem ou não algum tipo de conteúdo de mídia associado ao texto da postagem. Isso é mostrado na Tabela 3. E podemos interpretar os dados de uso mais significativo de conteúdos de mídia pelos usuários favoráveis ao ESP (87,4\% dos tweets desses indivíduos usam mídia, contra 72,8\% das mensagens contra ou neutras à causa) como parte de seu desejo de propagar a causa ${ }^{20}$.

A Tabela 4, na sequência, mostra o primeiro detalhamento sobre 0 tipo de conteúdo de mídia "comercial" ou de "conteúdo gerado pelo usuário" (CGU) - que se associa aos tweets ${ }^{21}$.

Tabela 3: Utilização de conteúdos de mídia associados aos tweets de usuários contra e favoráveis ao ESP

\begin{tabular}{c|c|c|c|c}
\hline \multirow{2}{*}{$\begin{array}{c}\text { Uso de mídia/ Posicionamento } \\
\text { do usuário }\end{array}$} & $\mathbf{N}$ & $\%$ & $\mathbf{N}$ & Nam \\
\cline { 2 - 5 } & 546 & 72,8 & 204 & 27,2 \\
\hline Contra/Neutro ao ESP & 6.659 & 87,4 & 956 & 12,6 \\
\hline Favorável ao ESP & $\mathbf{7 . 2 0 5}$ & $\mathbf{8 6 , 1}$ & $\mathbf{1 . 1 6 0}$ & $\mathbf{1 3 , 9}$ \\
\hline Total & & &
\end{tabular}

Fonte: Elaboração do autor

Tabela 4: Utilização de conteúdos de mídia associados aos tweets de usuários contra e favoráveis ao ESP

\begin{tabular}{c|c|c|c|c}
\hline \multirow{2}{*}{$\begin{array}{c}\text { Tipo de mídia/ Posicionamento } \\
\text { do usuário }\end{array}$} & \multicolumn{2}{|c|}{ Mídia comercial } & \multicolumn{2}{c}{ CGU } \\
\cline { 2 - 5 } & $\mathbf{N}$ & $\mathbf{N}$ & $\mathbf{N}$ & $\%$ \\
\hline Contra/Neutro ao ESP & 264 & 48,3 & 282 & 51,7 \\
\hline Favorável ao ESP & 1.141 & 17,1 & 5.518 & 82,9 \\
\hline Total & $\mathbf{1 . 4 0 3}$ & $\mathbf{1 9 , 5}$ & $\mathbf{5 . 8 0 2}$ & $\mathbf{8 0 , 5}$ \\
\hline
\end{tabular}

Fonte: Elaboração do autor retweetados do que tweets com outra forma (FERNANDES, 2018).

21 É importante esclarecer que adotamos uma definição ampla de CGU, praticamente em oposição à outra categoria ("mídia comercial"). É claro que seria possível entender que todos os tweets são "conteúdos gerados pelo usuário" (ou grupos/ coletivos de indivíduos que apoiam a causa), no entanto, o diferencial, para efeito de análise, é que ao tweet original foi associado algum tipo de mídia (foto, vídeo, etc.), não produzida por organismo de comunicação estritamente profissional. 
Os tweets produzidos pelos que apoiam o ESP utilizam bem mais os CGUs (82,9\% dos tweets com uso de mídia, contra 51,7\% dos tweets de usuários contrários), o que parece se associar a um maior engajamento na discussão. Por outro lado, são os tweets dos usuários contrários ao ESP que fazem mais uso da "mídia comercial" (48,3\%), enquanto os indivíduos favoráveis ao movimento utilizam-na menos (17,1\%). A já evidenciada relativa rejeição da proposta do ESP pelos veículos de comunicação pode justificar esse fato. $\mathrm{Na}$ Tabela 5, é feita a apresentação dos veículos que publicaram os conteúdos apropriados pelos usuários pró e contra o ESP.

Tabela 5: Veículos dos conteúdos utilizados nos tweets de usuários contra e a favor do ESP

\begin{tabular}{|c|c|c|c|c|}
\hline \multirow{2}{*}{ Veículo } & \multicolumn{2}{|c|}{ Usuários contra o ESP } & \multicolumn{2}{|c|}{ Usuários a favor do ESP } \\
\hline & $\mathbf{N}$ & $\%$ & $\mathbf{N}$ & $\%$ \\
\hline JornaLivre & - & - & $439\left(1^{\circ}\right)$ & 38,5 \\
\hline Gazeta do Povo & $4\left(11^{0}\right)$ & 1,5 & $161\left(2^{\circ}\right)$ & 14,1 \\
\hline G1 & $5\left(9^{\circ}\right)$ & 1,9 & $58\left(3^{\circ}\right)$ & 5,1 \\
\hline Veículos de órgãos legislativos/governamentais & $35\left(2^{\circ}\right)$ & 13,4 & $55\left(4^{0}\right)$ & 4,8 \\
\hline Conexão Política & - & - & $51\left(5^{\circ}\right)$ & 4,5 \\
\hline 0 Globo & $21\left(3^{\circ}\right)$ & 8,0 & $42\left(6^{0}\right)$ & 3,7 \\
\hline Opinião Crítica & - & - & $34\left(7^{\circ}\right)$ & 3,0 \\
\hline Extra & - & - & $29\left(8^{0}\right)$ & 2,5 \\
\hline 0 Estado de S. Paulo & - & - & $24\left(9^{\circ}\right)$ & 2,1 \\
\hline Folha de S. Paulo & $7\left(7^{\circ}\right)$ & 2,7 & $22\left(10^{\circ}\right)$ & 1,9 \\
\hline Instituto Liberal de São Paulo (ILISP) & - & - & $20\left(11^{\circ}\right)$ & 1,8 \\
\hline UOL & $3\left(12^{\circ}\right)$ & 1,1 & $14\left(12^{\circ}\right)$ & 1,2 \\
\hline Extra & - & - & $13\left(13^{\circ}\right)$ & 1,1 \\
\hline 0 Antagonista & - & - & $11\left(14^{0}\right)$ & 1,0 \\
\hline A Reunião & - & - & $9\left(15^{\circ}\right)$ & 0,8 \\
\hline Gospel Prime & - & - & $8\left(16^{\circ}\right)$ & 0,7 \\
\hline Bocão News & - & - & $8\left(16^{\circ}\right)$ & 0,7 \\
\hline Paraná Portal & - & - & $6\left(17^{\circ}\right)$ & 0,5 \\
\hline BBC & - & - & $5\left(19^{\circ}\right)$ & 0,4 \\
\hline IstoÉ & - & - & $5\left(19^{\circ}\right)$ & 0,4 \\
\hline Exame & - & - & $4\left(20^{\circ}\right)$ & 0,4 \\
\hline Ceticismo Político & - & - & $4\left(20^{\circ}\right)$ & 0,4 \\
\hline Imprensa Viva & - & - & $4\left(20^{\circ}\right)$ & 0,4 \\
\hline Nexo & $60\left(1^{0}\right)$ & 22,9 & - & - \\
\hline Carta Campinas & $21\left(3^{0}\right)$ & 8,0 & - & - \\
\hline Carta Capital/Carta Educação & $19\left(4^{0}\right)$ & 7,3 & - & - \\
\hline A Tarde & $10\left(5^{\circ}\right)$ & 3,8 & - & - \\
\hline Outros & 77 & 29,4 & 115 & 10,1 \\
\hline Total & 262 & 100,0 & 1.141 & 100,0 \\
\hline
\end{tabular}


Em primeiro lugar, a Tabela 5 mostra uma

discrepância quanto aos veículos de conteúdos informativos que os dois grupos utilizaram.

Essa diferença ressalta uma característica singular na apropriação da "mídia comercial" pelo grupo de apoiadores do movimento: o forte uso de publicações de veículos, exclusivamente on-line, não apenas alinhados com o ideário conservador (caso de Gazeta do Povo ${ }^{22}$ ), mas também de penetração restrita, com baixo nível de profissionalismo jornalístico e forte tendenciosidade. Na Figura 1, com exemplos de tweets desse tipo, pode-se observar que a imagem do meio é uma montagem grosseira. 0 principal veículo desse tipo é o JornaLivre, publicação nebulosa, com prováveis conexões com o MBL

(ALBUQUERQUE, 2017).

Figura 1: Exemplos de tweets de usuários a favor do ESP com uso da "mídia comercial"
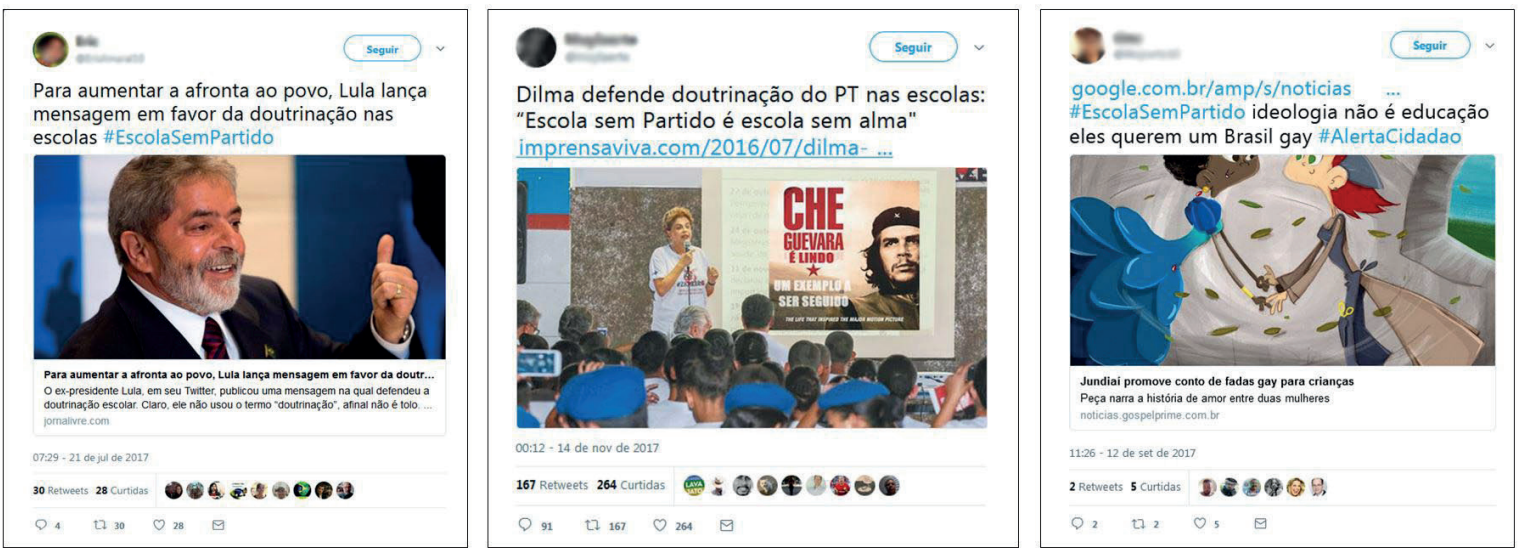

Fonte: https://goo.gl/ZhEJUs, https://goo.gl/Qx9qc1 e https://goo.gl/TcHvD2

Tais veículos parecem ter como objetivo agir como linhas auxiliares do ESP, desenvolvendo os itens da agenda do movimento, e incitando ações. Esse é 0 caso da matéria do Gospel Prime (à direita na Figura 1), redigida de modo a dar a entender que haveria "afronta moral" na montagem de uma peça infantil e que incitou petição digital de leitores para a sua retirada da programação cultural de uma cidade.

Deve-se notar, aliás, que as matérias apropriadas pelos usuários favoráveis ao ESP dividem-se entre

É válido notar que esse veículo lançou, em seis de dezembro de 2017, um espaço digital chamado "Monitor da Doutrinação", no qual leitores poderiam relatar casos de doutrinação em escolas. Mas, mostrando a dificuldade de a mídia de teor mais tradicional associar-se ao ESP, voltou atrás, retirando a plataforma da internet quatro dias depois. No texto de justificativa, é aceita a crítica de que "a ferramenta acabava por 'incitar, na escola, o clima de denuncismo e perseguição'" (GAZETA DO POV0, 2017). 
o eixo político e moral da "doutrinação" (o caso da peça é exemplo da crítica comum à "ideologia de gênero"). Esse aspecto da discussão, sugerido antes, é também reforçado na análise dos CGUs.
Quais são os tipos e as características desse conteúdo? A Tabela 6 faz uma aproximação a esse ponto, estabelecendo uma comparação entre os usuários contra e a favor do ESP.

Tabela 6: Tipos de conteúdos utilizados nos tweets sobre o ESP

\begin{tabular}{l|c|c|c|c}
\hline \multirow{2}{*}{ Tipo de conteúdo associado aos tweets } & \multicolumn{2}{c|}{ Usuários contra o ESP } & \multicolumn{2}{c}{ Usuários a favor do ESP } \\
\cline { 2 - 5 } & $\mathbf{N}$ & $\mathbf{\%}$ & $\mathbf{N}$ & $\%$ \\
\hline Vídeo & $22\left(5^{\circ}\right)$ & 7,8 & $2480\left(1^{\circ}\right)$ & 44,9 \\
\hline Imagem Estática & $46\left(2^{\circ}\right)$ & 16,3 & $2395\left(2^{\circ}\right)$ & 43,4 \\
\hline Postagem/Print do Facebook & $46\left(2^{\circ}\right)$ & 16,3 & $333\left(3^{\circ}\right)$ & 6,0 \\
\hline Tweet/Print de Tweet & $27\left(4^{\circ}\right)$ & 9,6 & $201\left(4^{\circ}\right)$ & 3,6 \\
\hline Link de transmissão de audiências & - & - & $39\left(5^{\circ}\right)$ & 0,7 \\
\hline PDF em plataforma web/Print de decisões judiciais & - & - & $17\left(6^{\circ}\right)$ & 0,3 \\
\hline Petição & $18\left(6^{\circ}\right)$ & 6,4 & $15\left(7^{\circ}\right)$ & 0,3 \\
\hline Texto de Blogs & $1\left(8^{\circ}\right)$ & 0,4 & $15\left(7^{\circ}\right)$ & 0,3 \\
\hline Postagem no Instagram & $1\left(8^{\circ}\right)$ & 0,4 & $10\left(8^{\circ}\right)$ & 0,2 \\
\hline Charge & $89\left(1^{\circ}\right)$ & 31,6 & $5\left(9^{\circ}\right)$ & 0,1 \\
\hline Twibbon & - & - & $4\left(10^{\circ}\right)$ & 0,1 \\
\hline Site Escola Sem Partido & - & - & $2\left(11^{\circ}\right)$ & 0,0 \\
\hline GIF animado & $\mathbf{2 8 2}$ & $\mathbf{1 0 0 , 0}$ & $\mathbf{5 . 5 1 8}$ & $\mathbf{1 0 0 , 0}$ \\
\hline Texto no Linkedin & $18\left(3^{\circ}\right)$ & 6,4 & $1\left(12^{\circ}\right)$ & 0,0 \\
\hline Twitter Moments & $6\left(7^{\circ}\right)$ & 2,1 & - & - \\
\hline Site Escola Partida & $4\left(8^{\circ}\right)$ & 1,4 & - & - \\
\hline Total & & 1,4 & $1\left(12^{\circ}\right)$ & 0,0 \\
\hline
\end{tabular}

Fonte: Elaboração do autor

Inicialmente, além do número absoluto bem maior de tweets dos usuários favoráveis ao ESP, é possível notar que eles parecem compreender características comunicacionais do Twitter que podem ajudar na disseminação dos conteúdos. Isso se depreende, por exemplo, pelo alto número de vídeos publicados, que são adaptados para a plataforma, tendo, assim, curta duração e linguagem simples.

Esses vídeos, cuja análise (junto com a das imagens estáticas) é priorizada, apresentam, entretanto, características que podem ser extrapoladas para os demais conteúdos 
agregados aos tweets. Desse modo, têm um caráter propagandístico e mobilizatório, sendo essas as principais preocupações dos usuários favoráveis ao ESP no Twitter. Muitos vídeos buscam "comprovar" a doutrinação realizada nas escolas brasileiras, por meio de depoimentos de pais e mesmo professores "arrependidos" ou "indignados". 0 emocionalismo, as vozes estridentes e 0 tom testemunhal, além do viés conservador, predominam (Figura 2).

Figura 2: Exemplos de tweets de usuários a favor do ESP com vídeos testemunhais
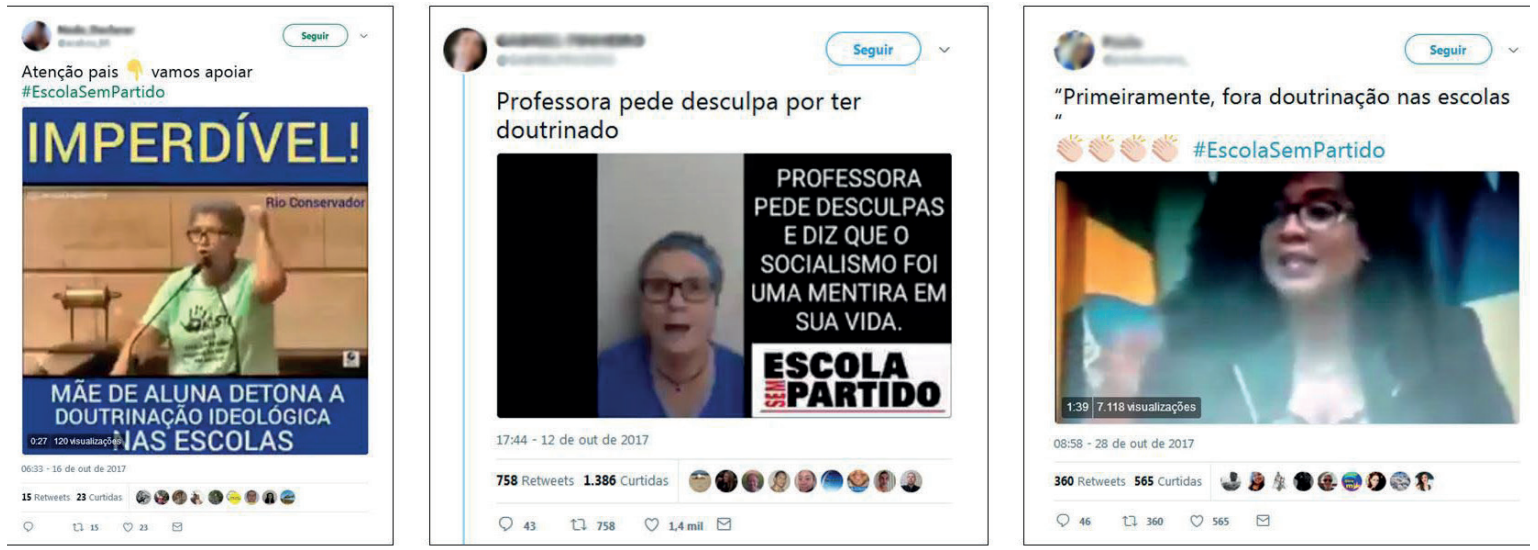

Fonte: https://goo.gl/qXZaqC, https://goo.gl/cRKXBF e https://goo.gl/5NXaLp

Silva Junior (2016, p. 51) observa, numa rede de canais de Facebook antipetistas, a predominância da crítica negativa ao governo/à candidatura de Dilma Rousseff, sem a feitura de propostas alternativas. Pode-se perceber algo similar entre os apoiadores do ESP. Assim, não é discernível um programa de reforma educacional que enfrente problemas concretos ${ }^{23}$, além da ideia de "impedir a doutrinação". Há, no máximo, alguns discursos de louvor aos "velhos tempos", quando os alunos não eram "lacradores", aprendiam "conteúdos disciplinares" (cf. 0 vídeo da Figura 2, à direita) e não havia violência nem imoralidade nas escolas.

A discussão do mérito do ESP é substituída pelos exemplos das "provas da doutrinação" que 0 movimento pretende eliminar. 0 conteúdo produzido pelos usuários (ou então editado

Entre outros, a evasão e o abandono escolar, que fazem com que apenas $59 \%$ dos jovens concluam o ensino médio com no máximo um ano de atraso (INSPER, 2017, p. 3). Talvez a ausência de propostas possa ser explicada pela "estratégia de oposição assimétrica no debate democrático" (DELCOURT, 2016, p. 134), adotada pela direita brasileira (de maneira similar ao Tea Party), isto é, o menor interesse em assumir governos e formular políticas do que em impedir a governabilidade de partidos progressistas. 
por eles, a partir de outras fontes, inclusive da mídia tradicional) é, por isso, importante. As situações criadas pela dinâmica da causa, tanto públicas (como as audiências de discussão de PLs e as mobilizações dos ativistas), quanto privadas (como os contextos escolares em que são registradas "provas"), oferecem oportunidades para gravações, eventualmente com dispositivos acessíveis, como os smartphones.

Isso é exemplificado por outro subtipo de tweet com vídeo/CGU comum: o de casos em que ocorre "doutrinação" em escolas, o que, aliás, está na origem do ESP. Como o entendimento do que seja a "doutrinação" é amplo, várias situações podem ser associadas ao tema. Por vezes, há certa descontextualização do registro para favorecer interpretações alarmistas - nos vídeos dos tweets da Figura 3, isso acontece de diferentes formas em cada um.

Pode-se dizer que, nesses e outros casos, há 0 desenvolvimento de um "discurso de ódio" ${ }^{24}$, já que, na tentativa de angariar adeptos, os participantes fazem uso de procedimentos como: "a seleção exclusiva de fatos favoráveis ao seu ponto de vista, a criação de 'inimigos', [...] uso de argumentos emocionais e da ausência de contraposição direta e imediata a tais mensagens" (SILVA et al. 2011, p. 448). 0s "doutrinadores" (professores, mas também políticos de esquerda) são os "inimigos" preferenciais.

Figura 3: Exemplos de tweets de usuários a favor do ESP com vídeos de registros de "doutrinação"
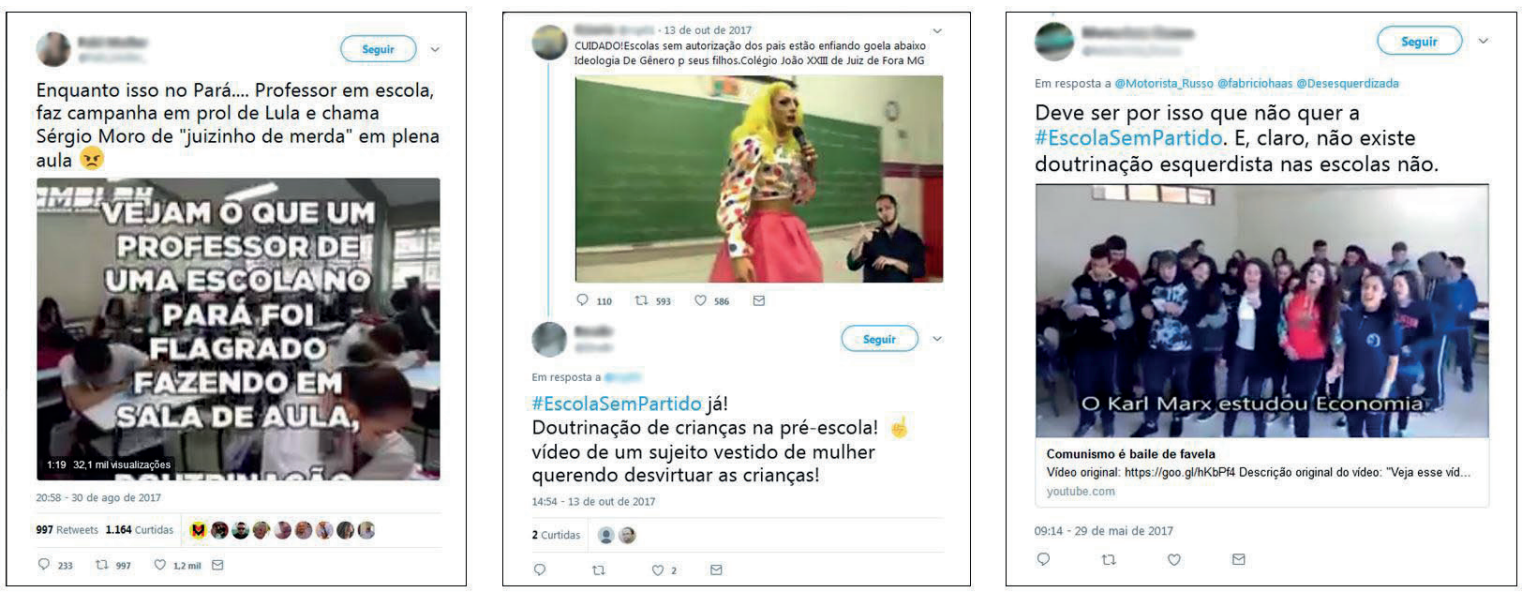

Fonte: https://goo.gl/mMnCWa, https://goo.gl/LVJqRg e https://goo.gl/EuEVAP 
Outro vídeo (com tipo diferente de "inimigo") merece menção: trata-se do CGU mais popular na discussão, com 501 retweets, que foi produzido pelo usuário18. Este indivíduo, na verdade, foi (e talvez ainda seja) funcionário do deputado Eduardo Bolsonaro ${ }^{25}$. Isso evidencia que 0 grau de "espontaneidade" no engajamento mobilizatório e o nível de "amadorismo" dos conteúdos elaborados pelos usuários são relativos. Porém, 0 víde $0^{26}$ possui traços da despretensão dos trabalhos de amadores. $\mathrm{Na}$ sintética gravação (dois minutos e meio), 0 homem fala para a câmera, numa crítica à série televisiva da Rede Globo Os dias eram assim, que estaria difamando o ESP. Desse modo, a

"Globo imunda" é atacada ${ }^{27}$. Um efeito sonoro e outro imagético buscam ridicularizar a cena e a fala de um parlamentar de esquerda mostrado. Temos aqui, então, um exemplo de uma prática comum na chamada mídia participativa: o remix de materiais preexistentes.

Isso ocorre em outros CGUs, principalmente em imagens estáticas, grupo composto por ampla gama de produções: fotos, cartazes com mensagens mobilizatórias, conteúdos associados ao ESP (como 0 logotipo da causa), imagens satíricas e memes (Figura 4).

Figura 4: Exemplos de tweets de usuários a favor do ESP com imagens estáticas
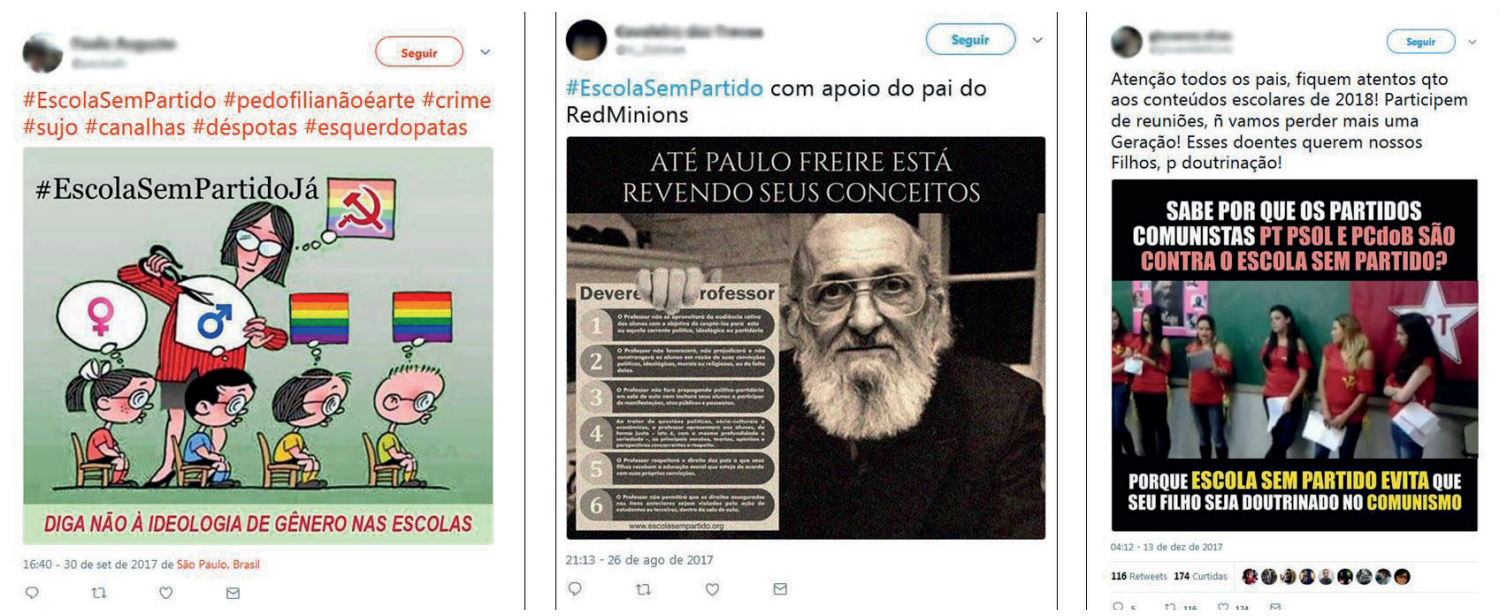

Fonte: https://goo.gl/9CrWnz, https://goo.gl/JrjLW5 e https://goo.gl/mzR5uV

Ver a postagem no grupo do Facebook "Pedala Direita": <https://goo.gl/17aJ23>. Acesso em: 07 nov. 2017.

26 Esse trabalho não pode mais ser visto no Twitter, já que a conta do usuário foi suspensa, porém, está disponível no YouTube: <https://goo.gl/pqVxk5>. Acesso em: 07 nov. 2017. 0 mesmo canal do YouTube desse indivíduo reúne vários vídeos de apoio ao deputado Jair Bolsonaro (PSL-RJ), entre eles um possível jingle de campanha presidencial - "Melhor Jair (se acostumando)" -, composto e interpretado por ele.

27 Isso também ocorre na discussão no Twitter, em relação ao programa Zorra Total com sátira ao ESP. Um tweet com trecho do programa e críticas a ele também foi bastante retweetado, com cerca de cem postagens. 
As temáticas da política ("doutrinação esquerdista") e moral (principalmente a "ideologia de gênero", mas também a "agenda LGBT", a "destruição das famílias" etc.), com compreensões abrangentes, e por vezes inusuais, do que essas questões representam são os elementos que impulsionam os conteúdos.

Desse modo, ao classificar uma amostra (de dez por cento do total) de tweets com CGUs dos favoráveis ao ESP, chega-se ao seguinte resultado (para os âmbitos em que os usuários apontam haver a doutrinação): $48 \%$ tweets indicam doutrinação política; 16\% moral e 8\% uma combinação das duas. Também surge nos tweets dos indivíduos em prol do ESP, embora em número menor (5\%), um tópico relevante: as mensagens que associam a "doutrinação" com a má qualidade da educação no país, a partir de dados informativos ou declarações dos usuários (Figura 5). Um tweet de Jair Bolsonaro combina os eixos político e moral com a questão da qualidade da educação: "0 ensino Brasil não sucumbe apenas por falta de dinheiro e péssima gestão, mas principalmente pela pauta de esquerda adotada pelos governantes, com 0 intuito exclusivo de formar militantes políticos”28.

Figura 5: Tweets de usuários a favor do ESP associando a qualidade da educação e a "doutrinação"
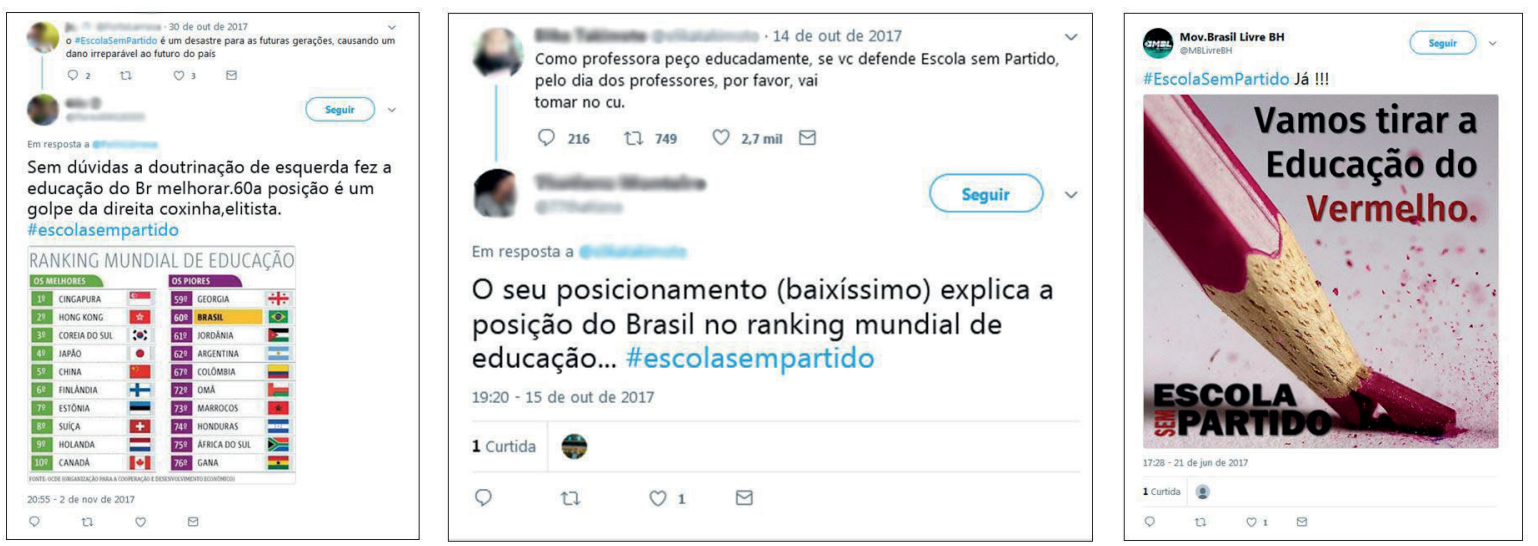

Fonte: https://goo.gl/B7dUq5, https://goo.gl/4jywMc e https://goo.gl/2Cd5Gk 
Pode-se finalizar, observando que os CGUs, de maneira geral, buscam convencer a partir de uma retórica emocional, com baixo desenvolvimento argumentativo, apelando a ideias de "salvação", "regeneração" e de "denúncia" da realidade da educação no Brasil. Assim, as interações entre os apoiadores caracterizam-se mais pela sintética concordância com o teor de alguma mensagem do que por discussão elaborada; por outro lado, as (poucas) comunicações entre usuários pró e contra o ESP tendem a terminar em ofensas mútuas.

\section{Considerações finais}

Podemos agora retomar as questões de pesquisa notando que, em relação à primeira, observouse uma significativa cobertura noticiosa sobre o movimento ESP. A real dimensão dessa cobertura, entretanto, merece ser investigada por outros estudos no futuro. Essa sugestão é feita, principalmente, pelo fato de que seria interessante perceber em que medida o ESP ocupa o lugar de outros assuntos e abordagens, no debate sobre a educação no Brasil. Como nota Schroeder, "ainda que os populistas recebam atenção negativa na mídia tradicional, isso priva os rivais políticos e os pontos de vista políticos alternativos de visibilidade"29 (2018, p. 79, tradução nossa). Outras sugestões para estudos futuros são: a comparação das ações comunicativas de movimentos de direita estrangeiros com os do Brasil ${ }^{30} \mathrm{e}$ entre 0 momento atual e anteriores quanto às preocupações dos conservadores locais com a educaçã $0^{31}$, análises do cruzamento entre as dinâmicas dos espaços on e off-line na constituição desses grupos ${ }^{32} \mathrm{e}$ sobre o papel comunicacional/político de seus líderes, como Jair Bolsonaro ${ }^{33}$.

No plano dos resultados, percebeu-se também que, de maneira geral, a mídia noticiosa aborda o ESP de forma neutra ou crítica. Talvez, por isso, o uso desse tipo de mídia (principalmente o jornalismo de referência) na discussão do Twitter seja relativamente baixo. Desse modo,

No original: "even if populists get negative attention in the mainstream media, this deprives political rivals and alternative political views of visibility".

Alega-se, por exemplo, influência do Tea Party no ideário da direita brasileira (DELCOURT, 2016); no entanto, no que esses movimentos se assemelham ou diferem em termos de estilos de comunicação merecem estudos.

310 trabalho de Cowan (2012) permite vislumbrar algumas similaridades entre a perspectiva sobre a educação dos elementos da "linha dura" do regime militar de 1964 e os partidários do ESP.

32 historiador Marco Antonio Villa, um expoente conservador atual, minimizou o papel da internet na constituição da "nova" direita (cf. NOGUEIRA, 2013). Porém, o conhecimento mais avançado sobre a questão deve ser ainda elaborado.

33 Uma indagação pertinente, feita por um parecerista, é sobre como se deve entender o "bolsonarismo". Esse trabalho não teve o propósito de trabalhar conceitualmente essa categoria, de modo que o termo foi utilizado de maneira pouco elaborada (como a ideologia dos usuários do Twitter que disseram apoiar esse deputado). É claro, pois, que é necessária uma exploração mais densa dessa categoria, quanto ao seu conteúdo e significado. Nessa perspectiva, as discussões de Telles sobre o papel do personalismo na dinâmica atual da direita brasileira, o fenômeno associado dos outsiders antissistema e a função das redes sociais na "emergência de lideranças com marcas neopopulistas, portadoras de preleções salvacionistas dirigidas aos grupos mais insatisfeitos" (2016, p. 118) podem ser úteis. 
os veículos tradicionais pouco colaboram para qualificar e estimular a discussão; ao contrário, pois um dos achados relevantes da investigação é a força da mídia "auxiliar" ao ESP (como 0 JornaLivre). Isso não chega a ser uma novidade - assim como o fenômeno associado das "notícias falsas" (fake news) -, pois a existência de veículos supostamente "independentes", mas partidarizados, é recorrente ao longo da história.

Porém, em tempos de midiatização e de internet, o que se deve destacar é a possibilidade de que a criação de veículos desse tipo cresça (em função dos menores custos de produção e da mais complexa repressão judicial a abusos $\left.{ }^{34}\right)$. A propagação dos conteúdos produzidos por eles também pode se acelerar, através de plataformas digitais de mídia social. Em relação ao uso dessa mídia nas redes digitais, isso pode favorecer as "câmeras de eco" nesses espaços, já que os materiais propagados tendem a reforçar, sem problematizações, as crenças dos indivíduos (BRIGHT, 2018).

Quanto a outras estratégias do movimento no Twitter, a própria expressiva produção de conteúdos pelos usuários (núcleo da segunda questão de pesquisa) representa uma espécie de alternativa ao impacto (qualitativo, principalmente) menor que o desejado na mídia tradicional. Há também ataques dos adeptos do ESP à mídia. Porém, as ações desse tipo foram pouco frequentes nos conteúdos informativos, sendo mais relevantes em produtos ficcionais da televisão. Talvez se reconheça, intuitivamente, uma maior capacidade de influência, na população em geral, no Brasil, dos produtos midiáticos de entretenimento, em comparação com os jornalísticos.

Os conteúdos produzidos pelos usuários desempenham um papel propagandístico e mobilizatório, com apelos emocionais, e sem que gerem diálogos significativos entre os indivíduos que participam da discussão mediada pela hashtag. Ao mesmo tempo, um primeiro aspecto de novidade na caracterização desse movimento conservador na internet é que há inexistência de controle comunicacional ${ }^{35}$, e os conteúdos são bem mais difundidos por perfis pessoais do que por contas institucionais (com a ressalva de que, como mostrado, militantes profissionais também se infiltram na discussão).

\section{Muitos CGUs utilizam técnicas, como a remediação de conteúdos e a remixagem dos mesmos, que são associadas à mídia participativa e à discussão política democrática (TOPINKA,}


2017), o que pode parecer paradoxal, dado 0 conservadorismo do ESP. No caso em estudo, isso aponta para outro aspecto emergente na caracterização dos grupos de direita na internet, isto é, o uso de estratégias mais próximas das lógicas comunicacionais da mídia na mobilização política. Isso pode estar relacionado tanto a características do Twitter quanto ao processo de midiatização da política em curso.

Porém, não se trata de algo inteiramente original, pois há trabalhos sobre grupos de direita internacionais (CAMMAERTS, 2007; TOPINKA, 2017) e nacionais (RIBEIR0; LASAITIS; GURGEL, 2016; SANTOS JUNIOR, 2016) que demostram que isso pode ocorrer. A utilização do humor, a criação de paródias e a reciclagem de materiais midiáticos na confecção de mensagens políticas, para 0 meio digital, não são monopólio da esquerda. Em outro contexto, Manovich já comentara algo válido também para a política: "Ao celebrar o conteúdo gerado pelo usuário e implicitamente qualificar 0 'conteúdo gerado pelo usuário' como 'alternativo' e 'progressista', as discussões acadêmicas, muitas vezes, ficam longe de perguntar certas questões críticas básicas" (2009, p. 286).
Como discutido antes, o ESP não chega a formular um programa articulado e amplo de reforma educativa. Insinua, porém, um projeto tradicionalista e conservador, em defesa da "lei e da ordem", para a educação. Essa proposta, além do prejuízo aos professores, tenderia a entrar em conflito com as demandas juvenis por escolas mais democráticas e participativas ${ }^{36}$. Portanto, pelas características mostradas ao longo do estudo, deve-se entender o ESP como parte da "nova" direita brasileira (última questão de pesquisa). A palavra de ordem "Sem partido!", das manifestações de 2013 (MISCHE, 2013; UOL, 2013), fortaleceu e deu reverberação a um movimento cujo foco na educação é profundamente político. A partir de interpretação enviesada de Gramsci ${ }^{37}$, a escola é vista como uma instância de formação ideológica da sociedade, que estaria "aparelhada" pelos esquerdistas. 0 remédio para isso seria a "escola sem partido".

Concluindo, seria interessante, a partir das análises, apontar uma implicação prática do trabalho: a recomendação para que os grupos progressistas abordem criticamente a associação entre "doutrinação" e má qualidade da educação

36 Aspecto que transpareceu no movimento de ocupações escolares (ROMANCINI; CASTILH0, 2017). A já mencionada reportagem de Dip (2016) traz alguns depoimentos de secundaristas sobre o ESP. Eles são majoritariamente contra, a partir de argumentos como: "Ainda rola o pensamento de que escola é para obedecer e não para questionar, e eu acho que esse projeto deve potencializar muito isso".

37 A crítica a Gramsci é comum na direita brasileira de maneira geral (DELCOURT, 2016). No caso do ESP, ela é efetuada também pela liderança do movimento. Assim, Miguel Nagib compartilhou em sua conta no Facebook um meme no qual Gramsci é mostrado como um vampiro no caixão, recebendo uma estaca que simboliza o ESP - disponível em: <https:// goo.gl/KpGNqd>, acesso em: 25 nov. 2017. A leitura de Gramsci por grupos de direita parece inusitada, mas tem precedente na extrema direta alemã, que, no final de década de 1990, chegou a buscar inspiração na teoria do autor italiano sobre a importância de adquirir predomínio sobre a vida cultural como pré-requisito para a mudança política (CHROUST, 2000). 
no país, por vezes postulada pelos defensores do ESP, procurando demostrar a falsidade dessa correlação para o público em geral.

\section{Referências}

AÇÃo Educativa (Ed.). A ideologia do movimento

Escola Sem Partido - 20 autores desmontam 0 discurso. São Paulo: Ação Educativa, 2016. Disponível em: < https://goo.gl/x2SJyt> . Acesso em: 07 nov. 2017.

ALBUQUERQUE, Ana Luiza. De olho em 2018, MBL aposta em apelo emocional e ataques à imprensa. Folha de S.Paulo, São Paulo, 27 de set. 2017. Disponível em: < https://g0o.gl/3a5W5M>. Acesso em: 28 dez. 2017.

ALMEIDA NETO, Antonio Simplicio de; SILVA, Diana Mendes Machado da. Escola Sem Partido ou sem autonomia? 0 cerco ao sentido público da educação. In: MACHADO, André Roberto de A.; TOLED0, Maria Rita de Almeida (Orgs.). Golpes na História e na Escola: o Brasil e a América Latina nos séculos XX e XXI. São Paulo: Cortez/ANPUH-SP, 2017.

ATTON, Chris. Far-right media on the internet: culture discourse and power. New Media \& Society, v. 8, n. 4, p. $573-587,2006$.

AZEVED0, Reinaldo. Barroso, aquele que não quer o 'Escola Sem Partido', tentou emplacar o 'Escola Sem Deus'. Perdeu! Folha de S. Paulo, São Paulo, 29 de set. 2017. Disponível em: < https://goo.gl/xfzjDv> . Acesso em: 28 dez. 2017.

BAUER, Martin W. A análise de conteúdo clássica: uma revisão. In: BAUER, Martin W.; GASKELL, George (Eds.). Pesquisa qualitativa com texto, imagem e som: um manual prático, Petrópolis: Vozes, 2002.

BRIGHT, Jonathan. Explaining the emergence of political fragmentation on social media: The role of ideology and extremism. Journal of ComputerMediated Communication (DOI: https://doi. org/10.1093/jcmc/zmx002), v. 23, n. 1, p. 17-33, 2018.
BRUNS, Axel; BURGESS, Jean. Twitter hashtags from ad hoc to calculated publics. In: RAMBUKKANA, Nathan (Ed.). Hashtag Publics: The Power and Politics of Discursive Networks. Peter Lang, New York, 2015.

CABLE, Jonathan. Communication Sciences and the Study of Social Movements. In: ROGGERBAND, Conny; KLANDREMANS, Bert (Eds.). Handbook of Social Movements Across Disciplines. 2. ed. Cham: Springer, 2017.

CAMMAERTS, Bart. Jamming the Political: Beyond Counter-hegemonic Practices, Continuum (D0I: http:// dx.doi.org/10.1080/10304310601103992) , v. 21, n. 1, p. 71-90, 2007.

. Radical pluralism and free speech in online public spaces: The case of North Belgian extreme right discourses. International Journal of Cultural Studies (D0I: http://dx.doi.org/10.1177/1367877909342479), v. 12 , n. 6, p. 555-575, 2009.

CASTELLS, Manuel. Communication Power. Oxford: Oxford University Press, 2009.

CHROUST, Peter. Neo-Nazis and Taliban on-line: anti-modern political movements and modern media. Democratization (D0I: https://doi. org/10.1080/13510340008403647), v. 7, n. 1, p. 102-119, 2000.

COWAN, Benjamim. "Why Hasn't This Teacher Been Shot?" Moral-Sexual Panic, the Repressive Right, and Brazil's National Security State. Hispanic American Historical Review (DOI: https://doi. org/10.1215/00182168-1600279), v. 92, n. 3, p. 403436, ago. 2012.

DELCOURT, Laurent. Um TeaParty tropical: a ascensão de uma "nova direita" no Brasil. Lutas Sociais, São Paulo, v. 20 n. 36, p. 126-139, jan./jun. 2016. Disponível em: < https://goo.gl/VUan9u > . Acesso em: 10 mar. 2018. DIP, Andrea. Escola Sem Partido caça bruxas nas salas de aula. Pública, 30 de ago. 2016. Disponível em: < https://g0o.gl/gkblqd > . Acesso em: 07 nov. 2017. 
EKMAN, Mattias. The dark side of online activism: Swedish right-wing extremist video activism on YouTube. MedieKultur, n. 56, p. 79-99, 2014.

ENGESSER, Sven; ERNST, Nicole; ESSER, Frank; BÜCHEL, Florin. Populism and social media: how politicians spread a fragmented ideology. Information, Communication \& Society (D0I: https://doi.org/10.1 080/1369118X.2016.1207697), v. 20, n. 8, p. 1109-1126, 2017.

ESPINOSA, Betty R. Solano; QUEIR0Z, Felipe B. Campanuci. Breve análise sobre as redes do Escola sem Partido. In: FRIG0TTO, Gaudêncio (Org.). Escola "Sem" Partido - Esfinge que ameaça a educação e a sociedade brasileira. Rio de Janeiro: Laboratório de Políticas Públicas da UERJ, 2017.

FAGANELLO, Marco Antonio. Bancada da Bala: uma onda na maré conservadora. In: VELASCO E CRUZ, Sebastião; KAYSEL, André; CODAS, Gustavo (Orgs.). Direita, volver!: o retorno da direita e o ciclo político brasileiro. São Paulo: Editora Fundação Perseu Abramo, 2015.

FERNANDES, Anaïs. Com 280 caracteres, Twitter tem $1^{0}$ lucro. Folha de S.Paulo, São Paulo, 08 fev. 2018. Disponível em: < https://goo.gl/t85hQ9> . Acesso em: 12 mar. 2018.

FIGUEIRAS, Rita. A mediatização da política na era das redes sociais. Lisboa: Aletheia, 2017.

FOLHA de S.Paulo. Na base da ideologia. São Paulo, 15 de maio 2016. Disponível em: < https://goo.gl/Cgxc31> . Acesso em: 28 dez. 2017.

\section{FRIG0TT0, Gaudêncio (Org.). Escola "Sem" Partido}

- Esfinge que ameaça a educação e a sociedade brasileira. Rio de Janeiro: Laboratório de Políticas Públicas da UERJ, 2017. Disponível em < https://goo.gl/ m5yTWv>. Acesso em: 07 nov. 2017.

GAZETA do Povo. Gazeta do Povo tira do ar "Monitor da Doutrinação". Entenda por quê. Curitiba, 10 dez. 2017. Disponível em: < https://goo.gl/xRsBbA> Acesso em 20 dez. 2017.

\section{INSPER. Políticas Públicas para Redução do} Abandono e Evasão Escolar de Jovens. São Paulo: Fundação Brava, Instituto Unibanco e Instituto Ayrton Senna, 2017. Disponível em: < https://goo.gl/sQvwga > . Acesso em 10 mar. 2018.

KAYSEL, André. Regressando ao Regresso: elementos para uma genealogia das direitas brasileiras. In: VELASCO E CRUZ, Sebastião; KAYSEL, André; CODAS, Gustavo (Orgs.). Direita, volver!: o retorno da direita e o ciclo político brasileiro. São Paulo: Editora Fundação Perseu Abramo, 2015. p. 49-74.

LIMA, Venício A. de. A direita e os meios de comunicação. In: VELASCO E CRUZ, Sebastião; KAYSEL, André; CODAS, Gustavo (Orgs.). Direita, volver!: 0 retorno da direita e o ciclo político brasileiro. São Paulo: Editora Fundação Perseu Abramo, 2015.

MANOVICH, Lev. A Prática da Vida (Midiática)

Cotidiana. Lugar Comum, n. 28, p. 283-296, 2009.

MAZZOLENI, Gianpietro. Mediatization and Political Populism. In: ESSER, Frank; STRÖMBÄCK, Jesper (Eds.). Mediatization of Politics: Understanding the Transformation of Western Democracies. Nova Iorque: Palgrave Macmillan, 2014.

MESSENBERG, Débora. A direita que saiu do armário: a cosmovisão dos formadores de opinião dos manifestantes de direita brasileiros. Sociedade e Estado, Brasília (D0I: http://dx.doi.org/10.1590/s010269922017.3203004), v. 32, n. 3, set./dez. 2017.

MIGUEL, Luís Felipe. Da "doutrinação marxista" à "ideologia de gênero" - Escola Sem Partido e as leis da mordaça no parlamento brasileiro. Direito \& Práxis (D0I: http://dx.doi.org/10.12957/dep.2016.25163), vol. 7, n. 3, p. 590-621, 2016.

MISCHE, Ann. "Come to the streets, but without parties": The challenges of the new Brazilian protests. Mobilizing Ideas, 4 set. 2013. Disponível em: < https:// goo.gl/nXJT11>. Acesso em: 10 mar. 2018.

NOGUEIRA, Paulo. Eles querem endireitar o Brasil. 
Unespciência, São Paulo, ano 4, n. 42, p. 18-25, jun. 2013. Disponível em: < https://g0o.gl/YtLQc9>. Acesso em 10 mar. 2018.

PADOVANI, Cinzia. The media of the ultra-right: Discourse and audience activism online. Journal of Language and Politics (DOI: http://dx.doi.org/10.1075/ jlp.15.4.02pad), v. 15, n. 2, p. 399-421, 2016.

PENNA, Fernando de Araujo. 0 Escola sem Partido como chave de leitura do fenômeno educacional. In: FRIG0TT0, Gaudêncio (Org.). Escola "sem" partido: esfinge que ameaça a educação e a sociedade brasileira. Rio de Janeiro: UERJ, LPP, 2017.

PIERUCCI, Antônio Flávio. As bases da nova direita.

Novos Estudos Cebrap, São Paulo, v. 3, n. 19, p. 26-45, dez. 1987. Disponível em: < https://goo.gl/tFCt94> Acesso em: 10 mar. 2018.

RAMOS, Marise Nogueira. Escola sem Partido: a criminalização do trabalho pedagógico. In: FRIGOTTO, Gaudêncio (Org.). Escola "sem" partido: esfinge que ameaça a educação e a sociedade brasileira. Rio de Janeiro: UERJ, LPP, 2017.

RIBEIR0, Luís Guilherme Marques; LASAITIS, Cristina; GURGEL, Lígia. Bolsonaro Zuero 3.0: Um estudo sobre as novas articulações do discurso da direita brasileira através das redes sociais. Anagrama, São Paulo, v. 10, n. 2, p. 1-16, jul./dez. 2016. Disponível em: < https:// goo.gl/QFPj2m>. Acesso em: 12 mar. 2018.

ROMANCINI, Richard; CASTILHO, Fernanda. "Como ocupar uma escola? Pesquiso na Internet!": política participativa nas ocupações de escolas públicas no Brasil. Revista Brasileira de Ciências da Comunicação (DOI: http://dx.doi.org/10.1590/18095844201726), São Paulo, v. 40, n. 2, p. 93-110, 2017.

RUCHT, Dieter. The quadruple 'A': Media strategies of protest movements since the 1960s. In: DE DONK, Wim Van et al. (Eds.). Cyberprotest: new media, citizens and social movements. Londres; Nova Iorque: Routledge, 2004.
Protest movements and their media usages.

In: CAMMAERTS, Bart; MATTONI, Alice; MCCURDY, Patrick (Eds.). Mediation and Protest Movements. Bristol, UK; Chicago, USA: Intellect, 2013.

SAAD-FILHO, Alfredo; BOIT0, Armando. Brazil: the failure of the PT and the rise of the "new right". In: PANITCH, Leo; ALB0, Greg (Eds.). The Politics of the Right: Socialist Register 2016. Nova Iorque: NYU Press, 2015.

SANTOS JUNIOR, Marcelo Alves dos. Vai pra Cuba!!! A Rede Antipetista na eleição de 2014. UFF, 2016. 197 f. Dissertação (Mestrado em Comunicação) Universidade Federal Fluminense, Niterói, RJ, 2016. Disponível em: < https://goo.gl/yktVdL> Acesso em: 10 mar. 2018.

SCHROEDER, Ralph. Social Theory after the

Internet: Media, Technology and Globalization.

Londres: UCL Press, 2018.

SILVA, Rosane Leal da; NICHEL, Andressa; MARTINS, Anna Clara Lehmann; BORCHARDT, Carlise Kolbe. Discursos de ódio em redes sociais: jurisprudência brasileira. Revista Direito GV (D0I: http://dx.doi. org/10.1590/S1808-24322011000200004), São Paulo, v. 7, n. 2, p.445-468, jul./dez. 2011.

SILVEIRA, Sergio Amadeu. Direita nas redes sociais online. In: VELASCO E CRUZ, Sebastião; KAYSEL, André; CODAS, Gustavo (Orgs.). Direita, volver!: o retorno da direita e o ciclo político brasileiro. São Paulo: Editora Fundação Perseu Abramo, 2015..

SIMPSON, Patricia Anne; DRUXES, Helga. Introduction. In: SIMPSON, Patricia Anne; DRUXES, Helga (Eds.).

Digital media strategies of the far-right in Europe and the United States. Lanham: Lexington, 2015.

SOLNIK, Alex. Vanguarda popular: a direita sai do armário (com roupas de esquerda). Brasileiros, n. 62, dez. 2012. Disponível em: < https://goo.gl/7zHYFg>. Acesso em: 10 mar. 2018.

SPONHOLZ, Liriam. Hate speech in the Mainstream Media: Transforming conflict dynamics through 
different narratives. In: CONFERENCE "NARRATIVES

OF PEACE AND CONFLICT", 2015, Liverpool. Anais

eletrônicos... Liverpool: Liverpool Hope University;

Archbishop Desmond Tutu Centre for War and

Peace Studies 2015. Disponível em: < https://goo.gl/

bQDAsc > . Acesso em: 10 mar. 2018.

STRÖMBÄCK, Jesper; ESSER, Frank. Mediatization of Politics: Towards a Theoretical Framework. In: ESSER, Frank; STRÖMBÄCK, Jesper (Eds.). Mediatization of Politics: Understanding the Transformation of Western Democracies. Nova Iorque: Palgrave Macmillan, 2014.

TATAGIBA, Luciana; TRINDADE, Thiago; TEIXEIRA, Ana Claudia Chaves. Protestos à direita no Brasil (2007-2015). In: VELASCO E CRUZ, Sebastião; KAYSEL, André; CODAS, Gustavo (Orgs.). Direita, volver!: o retorno da direita e o ciclo político brasileiro. São Paulo: Editora Fundação Perseu Abramo, 2015.

TELLES, Helcimara. A Direita Vai às Ruas: 0 antipetismo, a corrupção e democracia nos protesto antigoverno. Ponto e Vírgula, São Paulo, n. 19, p. 97-125, $1^{0}$ sem. 2016. Disponível em: < https://goo.gl/ cpYDKL > . Acesso em: 10 mar. 2018.

TOPINKA, Robert J. Politically incorrect participatory media: Racist nationalism on r/ImGoingToHellForThis. New Media \& Society (D0I: https://doi. org/10.1177/1461444817712516), jun. 2017.

UOL. "Sem partido!", gritam manifestantes contra uso de bandeiras em protesto em SP. UOL - Cotidiano, São Paulo, 17 jun. 2013. Disponível em: < https://goo.gl/ PdMd8j> . Acesso em: 10 mar. 2018.

VAN KESSEL, Stijn; CASTELEIN, Remco. Shifting the blame. Populist politicians' use of Twitter as a tool of opposition. Journal of Contemporary European Research, v. 12, n. 2, p. 594-614, 2016.

VELASC0 E CRUZ, Sebastião; KAYSEL, André; CODAS, Gustavo (Orgs.). Direita, volver!: o retorno da direita e o ciclo político brasileiro. São Paulo: Editora Fundação Perseu Abramo, 2015. 


\section{"Let's get education out} of the red": the Unpolitical

\section{School in digital networks}

\section{Abstract}

The article draws on a case study of Unpolitical School (US) movement, which combines analysis of the news coverage and the performance of individuals and institutions that use the social network Twitter (from the \# escolasempartido [\# unpoliticalschool] hashtag). The theoretical background involves the issue of mediatization of politics and contemporary digital activism. As results, it is possible to highlight: media coverage is generally neutral or unfavorable to US, the discussion on Twitter is held mostly by supporters of the cause, with significant use of low-quality media; many tweets use participatory media techniques.

\section{Keywords}

Unpolitical School. Digital Activism. Mediatization.

\section{"Vamos a sacar la educación} del rojo": el Escuela sin Partido en las redes digitales

\section{Resumen}

El artículo presenta un estudio de caso del movimiento Escuela Sin Partido (ESP), que combina análisis de la cobertura noticiosa y de la actuación de individuos e instituciones que utilizan la red social Twitter (a partir del hashtag \# escolasempartido [\# escuelasinpartido]). El telón de fondo teórico involucra la cuestión de la mediatización de la política y el activismo digital contemporáneo. En términos de resultados, es posible destacar: la cobertura de los medios informativos es generalmente neutra 0 desfavorable al ESP; la discusión en Twitter es realizada mayoritariamente por los partidarios de la causa, con uso significativo uso de medios de comunicación de baja calidad; muchos tweets utilizan técnicas de la comunicación mediática participativa.

\section{Palabras-clave}

Escuela Sin Partido. Activismo digital. Mediatización. 
